\title{
Relationship between serum IL-1 $\beta$ and insomnia and liver depression in patients with perimenopausal non-organic sleep disorder
}

\author{
HONG LI ${ }^{1-3 *}$, YING CHEN ${ }^{1-3 *}$, HAIHONG WU ${ }^{4}$, JUKAI HUANG ${ }^{5}$, \\ $\mathrm{KUN} \mathrm{MA}^{1-3}$, JIANGQIN ZHENG ${ }^{1-3}$ and SHAOGUANG LV ${ }^{1-3}$ \\ ${ }^{1}$ Department of Traditional Chinese Medicine, Provincial Clinical Medical College of Fujian Medical University; \\ ${ }^{2}$ Department of Traditional Chinese Medicine, Fujian Provincial Hospital; \\ ${ }^{3}$ Department of Traditional Chinese Medicine, Jinshan Branch of Fujian Provincial Hospital; \\ ${ }^{4}$ Department of Endocrinology, Fuzhou Traditional Chinese Medicine Hospital, Fuzhou, Fujian 350001; \\ ${ }^{5}$ College of the Second Clinical Medicine, Beijing University of Chinese Medicine, Beijing 100029, P.R. China
}

Received April 11, 2018; Accepted September 24, 2018

DOI: $10.3892 /$ etm.2018.6990

\begin{abstract}
The aim of the study was to detect the expression of interleukin-1 $\beta$ (IL-1 $\beta$ ) in serum of patients with perimenopausal non-organic sleep disorder (PNSD) and to study the relationship between IL-1 $\beta$ and the severity of insomnia and liver depression, so as to benefit the prevention of PNSD. A total of 268 cases of perimenopausal patients from the Department of Traditional Chinese Medicine of Fujian Provincial Hospital and the Department of Traditional Chinese Medicine of Jinshan Branch of Fujian Provincial Hospital were selected from March 2014 to June 2017. Among them, 182 patients developed non-organic insomnia (observation group). The remaining 86 patients were included in the control group. Serum levels of IL-1 $\beta$ were measured by enzyme-linked immunosorbent assay (ELISA). Scores of liver depression were determined and graded. Pittsburgh Sleep Quality Index (PSQI) was used to assess the severity of insomnia. Spearman's correlation analysis was used to analyze the correlation between PSQI, IL-1 $\beta$ and liver depression grade. Scores of liver depression in the observation group were significantly higher than those in control group $(\mathrm{p}<0.05)$. In the observation group, and PSQI scores in patients with different grades of liver depression are significantly different
\end{abstract}

Correspondence to: Dr Hong Li, Department of Traditional Chinese Medicine, Provincial Clinical Medical College of Fujian Medical University, 134 Dong Street, Fuzhou, Fujian 350001, P.R. China

E-mail: kyss866@126.com; 913836396@qq.com

*Contributed equally

Key words: perimenopause, non-organic sleep disorder, interleukin-1 $\beta$, liver depression score, insomnia, Pittsburgh Sleep Quality Index score $(\mathrm{p}<0.05)$. Average level of IL-1 $\beta$ in the observation group was significantly higher than that in control group $(\mathrm{p}<0.05)$. With the increase of liver depression grade, the expression level of IL-1 $\beta$ was also increased $(\mathrm{p}<0.05)$. Spearman's correlation analysis showed that PSQI was positively correlated with liver depression score, and the level of IL-1 $\beta$ was positively correlated with the liver depression grade in patients with PNSD. $(r=0.724, p=0.012 ; r=0.765, p=0.008)$. Expression of IL-1 $\beta$ in women with PNSD is significantly upregulated, and different degrees of liver depression also exist. Higher expression level of IL-1 $\beta$ is accompanied by more serious liver depression and higher degree of insomnia.

\section{Introduction}

Perimenopause refers to the physiological process in females form ovarian function begins to decline to 1 year after menopause $(1,2)$. Ovarian dysfunction and unstable expression of sex hormones can cause women's menopause syndromes, among which insomnia is one of the most common types $(3,4)$. Incidence of insomnia is $\sim 30-60 \%$, and with the growth of aging population, the incidence of insomnia is predicted to be further increased (5). Long-term insomnia not only has a great impact on the patient's normal activities but also reduces the patient's physiological function and causes a series of complications $(6,7)$. Therefore, it is necessary to pay attention to the problem of insomnia in perimenopausal women.

At present, the mechanism of insomnia in perimenopausal women is still unclear. Many studies have reported that liver depression plays a pivotal role in insomnia during perimenopausal period. Liver depression, also known as stagnation of liver-qi syndrome, refers to liver failure and stagnation, manifested as emotional depression, chest or abdominal distension, pain and so on. Those studies believed that insomnia in perimenopausal develops from liver $(8,9)$. Interleukin-1 $\beta$ (IL-1 $\beta$ ) is an important immune factor, and it is also a well-studied sleep-related cytokine in recent years (10). Rethorst et al (11) reported that IL-1 $\beta$ can effectively improve post-exercise 
narcolepsy in patients with depression. Zielinski et al (12) also found that the expression of IL- $1 \beta$ was significantly increased in patients with chronic sleep disorders. Therefore, a study of the relationship between IL-1 $\beta$ and insomnia in perimenopausal women is important for understanding its pathogenesis and clinical prevention and treatment.

In this study, the relationship between non-organic insomnia and the patient's liver depression score and serum IL-1 $\beta$ expression levels in perimenopausal women was studied. Our study provided guidance for clinical prevention and treatment of the perimenopausal non-organic sleep disorder (PNSD) in perimenopausal women.

\section{Materials and methods}

Research subjects. A total of 268 cases of perimenopausal patients from the Department of Traditional Chinese Medicine of Fujian Provincial Hospital and the Department of Traditional Chinese Medicine of Jinshan Branch of Fujian Provincial Hospital were selected from March 2014 to June 2017. Among them, 182 patients developed non-organic insomnia (observation group). The remaining 86 patients were included in the control group. Diagnostic criteria for perimenopausal women refer to 'Obstetrics and Gynecology'. Age range is 45-60 years. All patients had no menopause or menopause for $\leq 1$ year, and the follicle-stimulating hormone (FSH) was $>10$ IU/1. Diagnostic criteria for non-organic insomnia refer to the 'International Classification of Diseases, 10th edition (ICD-10, 2003)'. Patients suffered from sleep disorders, including difficulty falling asleep, poor quality of sleep, insomnia, for $>30$ days. The number of sleep disturbances occurred $\geq 3$ times a week, and sleep disturbances obviously caused the patient's distress or reduced social and professional functions. Patients with ovarian disease, unexplained irregular vaginal bleeding, a history of female and progesterone replacement therapy, cardiovascular disease and other organ diseases, autoimmune diseases, alcohol abuse, and smoking habit were excluded. The study was approved by the Ethics Committee of Provincial Clinical Medical College of Fujian Medical University (Fuzhou, China). Patients who participated in this research had complete clinical data. Signed written informed consents were obtained from the patients and/or guardians.

Specimen collection. Fasting venous blood $(5 \mathrm{ml})$ was extracted from those non-menopausal women in the morning of the first week of the menstrual cycle. Serum was separated within $1 \mathrm{~h}$ to detect IL-1 $\beta$.

$I L-1 \beta$ detection method. Expression of IL-1 $\beta$ in serum was detected by enzyme-linked immunosorbent assay (ELISA). Coating liquid was used to dilute IL-1 $\beta$, and $200 \mu \mathrm{l}$ of diluted IL- $1 \beta$ was added into each well, followed by incubation at $4^{\circ} \mathrm{C}$ overnight. After washing with $\mathrm{dd}_{2} \mathrm{O}$, blocking with blocking solution $(200 \mu \mathrm{l} /$ well $)$ was performed. Serum $(50 \mu \mathrm{l} /$ well $)$ was added, and negative NC, positive NC and blank control groups were set. Enzyme-labeled rabbit anti-human IL-1 $\beta$ polyclonal antibody (1:300, cat. no. 16806-1-AP, ProteinTech Group, Inc.; Wuhan Sanying Biotechnology, Wuhan, China) was added and incubated at $37^{\circ} \mathrm{C}$ for $45 \mathrm{~min}$. After washing
Table I. Clinical characteristics of the two groups of patients.

\begin{tabular}{lcccc}
\hline Variables & $\begin{array}{c}\text { Control } \\
\text { group (n=86) }\end{array}$ & $\begin{array}{c}\text { Observation } \\
\text { group }(\mathrm{n}=182)\end{array}$ & $\chi^{2} / \mathrm{t}$ & P-value \\
\hline Age (years) & $53.5 \pm 4.15$ & $54.9 \pm 4.55$ & 0.691 & 0.490 \\
FSH (IU/l) & 14.5 & 15.3 & 1.636 & 0.085 \\
LH (IU/l) & 5.4 & 7.7 & 1.942 & 0.051 \\
E2 (pg/ml) & 32.4 & 33.9 & 0.067 & 0.965 \\
T (ng/ml) & 0.14 & 0.15 & 0.412 & 0.633 \\
Depression & & & & \\
score & $45.69 \pm 10.47$ & $51.95 \pm 9.57$ & 4.849 & $<0.001$ \\
Anxiety score & $45.26 \pm 7.84$ & $51.29 \pm 10.32$ & 4.802 & $<0.001$ \\
Menopause & & & & \\
status [n (\%)] & & & 0.050 & 0.895 \\
Not menopause & $50(58.14)$ & $112(61.54)$ & & \\
Menopause & $36(41.86)$ & $70(38.46)$ & & \\
\hline
\end{tabular}

FSH, follicle-stimulating hormone; LH, luteinizing hormone; E2, estradiol; $\mathrm{T}$, testosterone.

for 5 times, $30 \mathrm{sec}$ to $1 \mathrm{~min}$ for each time, $100 \mu \mathrm{l}$ of substrate was added into each well, and incubation was performed at $37^{\circ} \mathrm{C}$ for $15 \mathrm{~min}$. Finally, the reaction was terminated by adding $0.05 \mathrm{ml}$ of sulfuric acid at $2 \mathrm{~mol} / 1$ per well. Color development was performed within $15 \mathrm{~min}$. The kit for IL-1 $\beta$ was purchased from Roche Diagnostics (Basel, Switzerland).

Observation indicators. Serum levels of IL-1 $\beta$ were measured by ELISA. According to the 'syndrome differentiation', weighted threshold method is used to determine the weight of disease location and venereal factors, and 100 is used as universal threshold to judge whether the diagnosis of each syndrome element is valid. If the symptom is severe, its quantitative diagnosis value multiplies 1.5 , if the symptom is mild, multiply 0.7 , and accumulate the contribution degree of the related elements of liver depression as the integral of liver depression syndrome element. Liver depression scores: score $<70$ as grade $0 ; \geq 70$ and $<100$ as grade $1 ; \geq 100$ and $<150$ as grade 2; $\geq 150$ as grade 3 (13). Pittsburgh Sleep Quality Index (PSQI) was used to assess 30-day insomnia severity.

Statistical analysis. Statistical analysis was performed by using SPSS 22.0 software [Asia Analytics (formerly SPSS China), Shanghai, China]. Count data are expressed as percentages and processed by $\chi^{2}$ test. Normal measurement data are expressed as mean \pm standard deviation (SD). Follicle-stimulating hormone (FSH), luteinizing hormone (LH), estradiol (E2) and testosterone $(\mathrm{T})$ did not meet the normal distribution and were expressed as median (M). Independent sample t-test was used for comparison between groups, and variance analysis was used for comparison among groups with LSD test as a post hoc test. Spearman's correlation analysis was used to analyze the relationship between IL-1 $\beta$ and PNSD and hepatic depression. $\mathrm{P}<0.05$ indicates that the difference was statistically significant. 
Table II. Results of liver depression scoring.

\begin{tabular}{lccrr}
\hline & $\begin{array}{c}\text { Control } \\
\text { Variables }\end{array}$ & $\begin{array}{c}\text { Observation } \\
\text { group }(\mathrm{n}=182)\end{array}$ & $\begin{array}{c}\chi^{2} / \mathrm{t} \\
\text { group }\end{array}$ & P-value \\
\hline $\begin{array}{l}\text { Average score } \\
\text { Depression }\end{array}$ & $108.5 \pm 57.6$ & $158.4 \pm 64.5$ & 6.113 & $<0.001$ \\
grades & & & & \\
$0[\mathrm{n}(\%)]$ & $32(37.21)$ & $23(12.64)$ & 20.139 & $<0.001$ \\
$1[\mathrm{n}(\%)]$ & $12(13.95)$ & $18(9.89)$ & 0.604 & 0.406 \\
$2[\mathrm{n}(\%)]$ & $16(18.60)$ & $46(25.27)$ & 1.110 & 0.278 \\
$3[\mathrm{n}(\%)]$ & $26(30.23)$ & $95(52.20)$ & 10.509 & 0.001 \\
\hline
\end{tabular}

Table III. Expression levels of IL-1 $\beta$ in the two groups of patients (pg/l).

\begin{tabular}{lclcr}
\hline Variables & $\begin{array}{c}\text { Control } \\
\text { group }(\mathrm{n}=86)\end{array}$ & $\begin{array}{c}\text { Observation } \\
\text { group }(\mathrm{n}=182)\end{array}$ & $\mathrm{t}$ & P-value \\
\hline Average level & $102.5 \pm 57.4$ & $147.6 \pm 65.9$ & 5.444 & $<0.001$ \\
Grade 0 & $74.1 \pm 23.4$ & $108.2 \pm 24.8$ & 2.365 & 0.018 \\
Grade 1 & $86.9 \pm 24.7^{\mathrm{a}}$ & $128.1 \pm 34.8^{\mathrm{a}}$ & 2.775 & 0.006 \\
Grade 2 & $107.6 \pm 46.7^{\mathrm{a}, \mathrm{b}}$ & $162.4 \pm 58.6^{\mathrm{a}, \mathrm{b}}$ & 3.508 & 0.001 \\
Grade 3 & $141.4 \pm 48.9^{\mathrm{a}-\mathrm{c}}$ & $191.7 \pm 64.2^{\mathrm{a}-\mathrm{c}}$ & 2.469 & 0.014
\end{tabular}

${ }^{\mathrm{a}} \mathrm{P}<0.05$, compared with grade $0 ;{ }^{\mathrm{b}} \mathrm{p}<0.05$, compared with grade 1 ; ${ }^{c} \mathrm{p}<0.05$, compared with grade 2 . IL- $1 \beta$, interleukin- $1 \beta$.

Table IV. Correlation analysis.

\begin{tabular}{lccc}
\hline Variables & IL-1 $\beta$ & PSQI & $\begin{array}{c}\text { Liver depression } \\
\text { score }\end{array}$ \\
\hline PSQI & $\mathrm{r}=0.812$ & & $\mathrm{r}=0.793$ \\
& $\mathrm{P}=0.002$ & & $\mathrm{P}=0.005$ \\
Liver depression & $\mathrm{r}=0.765$ & $\mathrm{r}=0.724$ & \\
score & $\mathrm{P}=0.008$ & $\mathrm{P}=0.012$ & \\
\hline
\end{tabular}

\section{Results}

General data. The average age of 182 PNSD patients in observation group was $54.9 \pm 4.55$ years. Eighty-six patients in control group were females in perimenopausal period without non-organic insomnia, and the average age was $53.5 \pm 4.15$ years. There were no differences in FSH, LH, E2, T levels, and menopausal status between the two groups $(\mathrm{p}>0.05)$. However, there was a difference in depression and anxiety scores between the two groups. Depression and anxiety scores in the observation group were higher than those in control group $(\mathrm{p}<0.05$, Table I).

Liver depression score results in the two groups. The liver depression scores in the observation group were significantly higher than those in control group $(\mathrm{p}<0.05)$. Liver depression

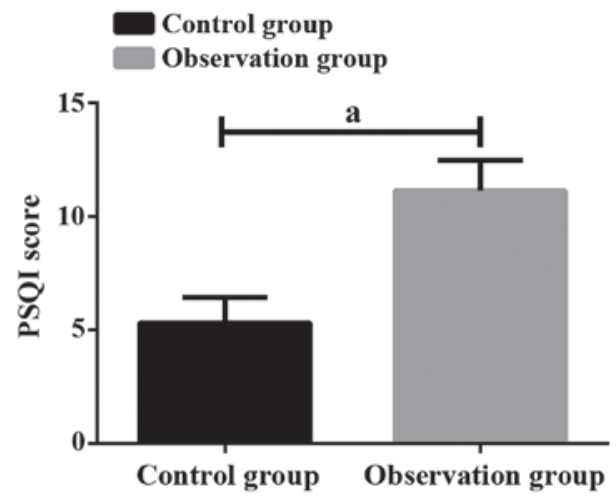

Figure 1. PSQI scores of the two groups of patients. PSQI score in control group was $5.32 \pm 1.11$, and in observation group was $11.15 \pm 1.33$. There was a significant difference between the two groups $(\mathrm{p}<0.05)$. ${ }^{\mathrm{a}} \mathrm{P}<0.05$. PSQI, Pittsburgh Sleep Quality Index

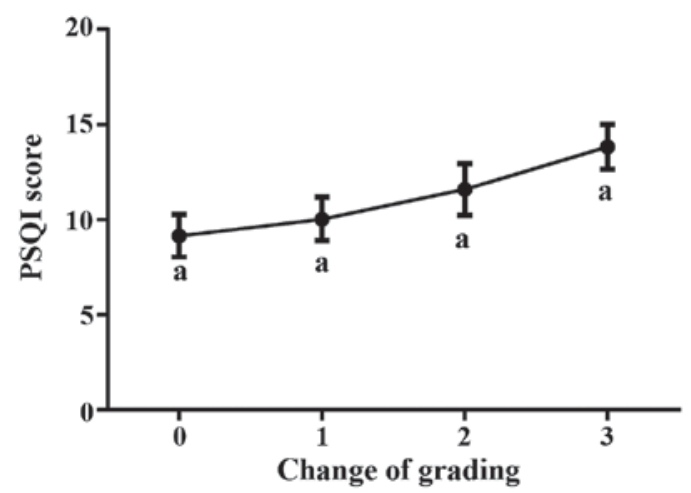

Figure 2. Relationship between PSQI scores and liver depression grades in the observation group. Higher liver depression grades were accompanied by higher PSOI scores, and the differences of PSOI scores between different liver depression grades were significant $(\mathrm{p}<0.05)$. Differences of PSOI scores between different liver depression grades were significant, ${ }^{\mathrm{a}} \mathrm{p}<0.05$. PSQI, Pittsburgh Sleep Quality Index.

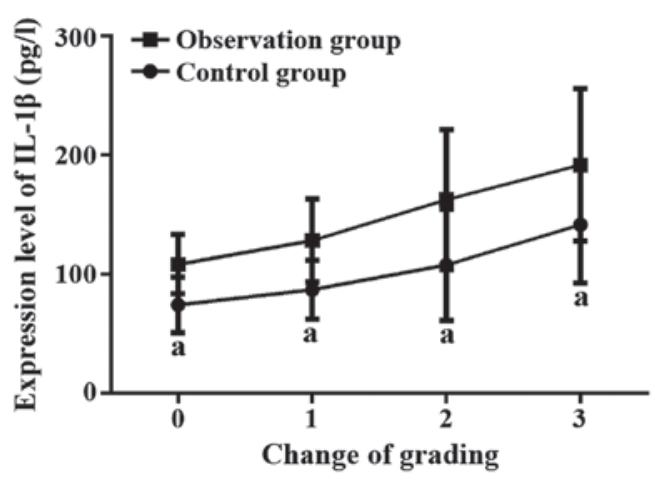

Figure 3. Levels of IL-1 $\beta$ expression in the two groups. Expression level of IL-1 $\beta$ was significantly higher in the observation group than in control group at each liver depression grade $(\mathrm{p}<0.05)$. Expression level of IL-1 $\beta$ was different in patients with different liver depression grades within the same group. Higher liver depression grades are accompanied by higher expression level of IL-1 $\beta(\mathrm{p}<0.05)$. ${ }^{\mathrm{a}} \mathrm{P}<0.05$, compared with observation group. IL-1 $\beta$, interleukin-1 $\beta$.

grading showed a significant difference between the two groups in proportion of patients with grade 0 and 3 liver depression, and the proportion of patients with grade 0 liver 
depression in control group was significantly higher than that in the observation group $(\mathrm{p}<0.05)$, while proportion of patients with grade 3 liver depression in the observation group was significantly higher than that in control group $(p<0.05)$. There was no significant difference between the two groups in the proportion of people with grade 1 and 2 liver depression ( $p>0.05$, Table II).

PSQI scores of the two groups of patients. Average PSQI score in control group was 5.32 \pm 1.11 , and average PSQI score in observation group was $11.15 \pm 1.33$. There was a significant difference between the two groups $(\mathrm{p}<0.05$, Fig. 1). Higher liver depression in observation group was accompanied by higher PSQI score. PSQI scores were significantly different in patients with different liver depression grades ( $p<0.05$, Fig. 2).

$I L-1 \beta$ expression levels in the two groups. The average expression level of IL-1 $\beta$ in the observation group was significantly higher than that in control group $(\mathrm{p}<0.05$, Table III). According to the liver depression grading results, the expression level of IL-1 $\beta$ was significantly higher in the observation group than in control group at each liver depression grade $(p<0.05)$. The expression level of IL-1 $\beta$ was different in patients with different liver depression grades within the same group. Higher liver depression grades are accompanied by higher expression level of IL-1 $\beta$ ( $\mathrm{p}<0.05$, Fig. 3).

Correlation analysis. Spearman's correlation analysis showed that PSQI was positively correlated with liver depression score, and the level of IL-1 $\beta$ was positively correlated with the liver depression grade in patients with PNSD $(\mathrm{r}=0.724, \mathrm{p}=0.012$; $\mathrm{r}=0.765, \mathrm{p}=0.008)($ Table IV).

\section{Discussion}

The most common type of perimenopausal sleep disorder is non-organic insomnia (14). Liver depression is one of the most important syndromes in patients with non-organic insomnia. Chinese medicine believes that liver blood deficiency can cause insomnia (15). Western medicine believes there is a close relationship between sleep and the immune system (16). IL-1 $\beta$ is an important immune factor regulating sleep arousal behavior. IL-1 $\beta$ can be transported through its IL- $1 \beta$ receptor to the site of action of NREM sleep in the preoptic area of the hypothalamus, which in turn regulates firing patterns of hypothalamus and brain stem neurons and sleep arousal activity $(17,18)$. In this study, the serum levels of IL-1 $\beta$ in 182 patients with PNSD were measured, and correlations with the degree of insomnia and the degree of liver depression were investigated. Our findings provided guidance for the clinical prevention and treatment of PNSD patients.

In this study, 182 PNSD patients were included in the observation group, and 86 perimenopausal healthy women were included in the control group. Results showed that PSQI scores of the observation group were significantly higher than those of control group. With high reliability and validity, PSQI can be used to subjectively evaluate severity of insomnia in the past 1 month, and it has become a commonly used clinical insomnia severity rating scale worldwide (19-21). In this study, liver depression scores were graded referred to 'syndrome differentiation' (13). Scores of liver depression in the observation group were significantly higher than those in control group, and most of PNSD patients had different degrees of liver depression. Patients with PNSD mostly showed grade 2 and 3 liver depression, and the proportion of grade 3 patients was significantly higher in the observation group than in control group, indicating that most patients with PNSD had moderate-to-heavy liver depression. Most perimenopausal healthy women had grade 0 liver depression, and the proportion of grade 0 patients was significantly higher in the control group than in observation group, indicating that perimenopausal healthy women usually do not suffer from liver depression. Results of this study also showed that with the increase in liver depression grade, PSQI scores and the severity of insomnia of patients in observation group were also getting higher and higher. Correlation analysis also showed that there was a positive correlation between the liver depression and the PSQI scores. We also measured the expression level of IL-1 $\beta$ in fasting blood. Test results showed that the expression level of IL-1 $\beta$ in the observation group was significantly higher than that in control group, and the expression level of IL-1 $\beta$ was also increased with the increase in grade of liver depression. Correlation analysis showed that the expression level of IL-1 $\beta$ was positively correlated with the liver depression grade and PSQI scores. Therefore, we can speculate that a higher expression level of IL-1 $\beta$ may cause more severe insomnia and higher degree of liver depression in PNSD patients. Animal experimental studies have found that high levels of oxidative stress and expression of IL-1 $\beta$ in the brain tissue of sleep-deprived animals $(22,23)$. IL-1 $\beta$ is a well-known sleep-regulating cytokine (24). Therefore, we speculate that PNSD patients have increased stress response, which stimulates IL-1 $\beta$ expression, so as to protect neurological function by regulating related neuroactive substances in patients with insomnia. Due to limited time, this study failed to further study the factors related to insomnia and sleep. In addition, the sample size of this study is also small. Further studies with bigger sample size are still needed to further confirm our conclusion.

In summary, the expression level of IL-1 $\beta$ in women with PNSD was significantly upregulated, and different degrees of liver depression also exist. Higher expression level of IL-1 $\beta$ is accompanied by more serious liver depression and higher degree of insomnia.

\section{Acknowledgements}

Not applicable.

\section{Funding}

This study was funded by the National Natural Science Foundation of China (General Program) (81473599), the Innovative Medical Project of Fujian Province (2016-CX-8), and the Youth Research Project of Fujian Province (2016-1-6).

\section{Availability of data and materials}

The datasets used and/or analyzed during the present study are available from the corresponding author on reasonable request. 


\section{Authors' contributions}

HL and YC wrote the manuscript and collected the specimens. $\mathrm{HW}$ and $\mathrm{JH}$ were responsible for ELISA. KM and JZ recorded and analyzed the PSQI. SL contributed to the statistical analysis. All authors read and approved the final manuscript.

\section{Ethics approval and consent to participate}

The study was approved by the Ethics Committee of Provincial Clinical Medical College of Fujian Medical University (Fuzhou, China). Patients who participated in this research had complete clinical data. Signed written informed consents were obtained from the patients and/or guardians.

\section{Patient consent for publication}

Not applicable.

\section{Competing interests}

The authors declare that they have no competing interests.

\section{References}

1. Martini J, Knappe S, Garthus-Niegel S and Hoyer J: Mental disorders in women: Natural course during premenstrual phases, peripartum period and perimenopause. Fortschr Neurol Psychiatr 84: 432-449, 2016 (In German).

2. Mosconi L, Berti V, Quinn C, McHugh P, Petrongolo G, Osorio RS Connaughty C, Pupi A, Vallabhajosula S, Isaacson RS, et al: Correction: Perimenopause and emergence of an Alzheimer's bioenergetic phenotype in brain and periphery. PLoS One 13: e0193314, 2018.

3. Weber MT, Maki PM and McDermott MP: Cognition and mood in perimenopause: A systematic review and meta-analysis. J Steroid Biochem Mol Biol 142: 90-98, 2014.

4. Brinton RD, Yao J, Yin F, Mack WJ and Cadenas E: Perimenopause as a neurological transition state. Nat Rev Endocrinol 11: 393-405, 2015

5. Mosconi L, Berti V, Guyara-Quinn C, McHugh P, Petrongolo G, Osorio RS, Connaughty C, Pupi A, Vallabhajosula S, Isaacson RS, et al: Perimenopause and emergence of an Alzheimer's bioenergetic phenotype in brain and periphery. PLoS One 12: e0185926, 2017.

6. Martin VT, Pavlovic J, Fanning KM, Buse DC, Reed ML and Lipton RB: Perimenopause and menopause are associated with high frequency headache in women with migraine: Results of the American Migraine Prevalence and Prevention Study. Headache 56: 292-305, 2016

7. Brooks HL, Pollow DP and Hoyer PB: The VCD mouse model of menopause and perimenopause for the study of sex differences in cardiovascular disease and the metabolic syndrome. Physiology (Bethesda) 31: 250-257, 2016

8. Guo HM, Liu M, Xiang YT, Zhao J, Ungvari GS, Correll CU, $\mathrm{Ng} \mathrm{CH}$, Chiu HF and Duan ZP: Insomnia in adults with chronic hepatitis B, liver failure, and cirrhosis: A case-control study. Perspect Psychiatr Care 53: 67-72, 2017.

9. Yeung WF, Chung KF, Zhang NL, Zhang SP, Yung KP, Chen PX and Ho YY: Identification of Chinese medicine syndromes in persistent insomnia associated with major depressive disorder: A latent tree analysis. Chin Med 11: 4, 2016.
10. Fu JJ, McDonald VM, Baines KJ and Gibson PG: Airway IL-1 $\beta$ and systemic inflammation as predictors of future exacerbation risk in asthma and COPD. Chest 148: 618-629, 2015.

11. Rethorst CD, Greer TL, Toups MS, Bernstein I, Carmody TJ and Trivedi MH: IL-1 $\beta$ and BDNF are associated with improvement in hypersomnia but not insomnia following exercise in major depressive disorder. Transl Psychiatry 5: e611, 2015.

12. Zielinski MR, Kim Y, Karpova SA, McCarley RW, Strecker RE and Gerashchenko D: Chronic sleep restriction elevates brain interleukin-1 beta and tumor necrosis factor-alpha and attenuates brain-derived neurotrophic factor expression. Neurosci Lett 580: 27-31, 2014

13. Wang SF, Wang Q, Jiao LJ, Huang YL, Garfield D, Zhang J and Xu L: Astragalus-containing Traditional Chinese Medicine, with and without prescription based on syndrome differentiation, combined with chemotherapy for advanced non-small-cell lung cancer: A systemic review and meta-analysis. Curr Oncol 23: e188-e195, 2016

14. Słopień R, Wichniak A, Pawlak M, Słopień A, WarenikSzymankiewicz A and Sajdak S: Disturbances of sleep continuity in women during the menopausal transition. Psychiatr Pol 49: 615-623, 2015.

15. Janjic V, Radmanovic B, Dejanovic SD, Ravanic D and Borovcanin M: P.8.b.006: Side effects of zolpidem and temazepam in treating primary insomnia. Eur Neuropsychopharmacol 24: S737-S738, 2014.

16. Black DS and Slavich GM: Mindfulness meditation and the immune system: A systematic review of randomized controlled trials. Ann N Y Acad Sci 1373: 13-24, 2016.

17. Talwar H, Bauerfeld C, Bouhamdan M, Farshi P, Liu Y and Samavati L: Corrigendum to 'MKP-1 negatively regulates LPS-mediated IL-1 $\beta$ production through $\mathrm{p} 38$ activation and HIF-1 $\alpha$ expression'. (Cell Signal. 34 (1-10) (2017) Epub 2017 Feb 24). Cell Signal 38: 239, 2017.

18. Lee WS, Choi YJ, Cheon YH, Hong MJ, Lee CH, Lee MS, Lee SI and Yoo WH: AB0146: Rebamipide inhibits IL-1 $\beta$-induced proliferation of rheumatoid arthritis synovial fibroblasts through the phosphor-Jun N-terminal kinase (P-JNK) pathway. Ann Rheum Dis 74: 939, 2015

19. Reis C, Pilz LK, Keller L, Roenneberg T and Paiva T: PSQI largely ignores sleep on work-free days both in the general population and in clinical sleep medicine samples. Sleep Med 40: e277, 2017.

20. Xia T, Li S, Ma R, Guan S, Li J, Li H, Zhang H, Lin Q, Zhao Z and Wang B: Effects of liver depression and psychological stress on human uterine leiomyoma cells by an AR-cAMP-PKA signal transduction pathway. Taiwan J Obstet Gynecol 56: 291-301, 2017.

21. Meller W, Welle N, Sutley K and Thurber S: Depression and liver transplant survival. Psychosomatics 58: 64-68, 2017.

22. Niznikiewicz MM, Gerashchenko D, Mckenna JT, Basheer R, Strecker RE, McCarley RW and Zielinski MR: 0021: Sleep deprivation activates NLRP3 inflammasomes in neurons and glia. Sleep 40 (suppl 1): A8, 2017.

23. Zielinski MR, Gerashchenko D, Karpova SA, Konanki V, McCarley RW, Sutterwala FS, Strecker RE and Basheer R: The NLRP3 inflammasome modulates sleep and NREM sleep delta power induced by spontaneous wakefulness, sleep deprivation and lipopolysaccharide. Brain Behav Immun 62: 137-150, 2017.

24. Chennaoui M, Gomez-Merino D, Drogou C, Geoffroy H, Dispersyn G, Langrume C, Ciret S, Gallopin T and Sauvet F: Effects of exercise on brain and peripheral inflammatory biomarkers induced by total sleep deprivation in rats. J Inflamm (Lond) 12: 56, 2015.

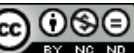

This work is licensed under a Creative Commons Attribution-NonCommercial-NoDerivatives 4.0 International (CC BY-NC-ND 4.0) License. 